This item was submitted to Loughborough's Research Repository by the author.

Items in Figshare are protected by copyright, with all rights reserved, unless otherwise indicated.

\title{
The assessment of coarse granular materials for performance based
} pavement foundation design

PLEASE CITE THE PUBLISHED VERSION

PUBLISHER

(c) Taylor \& Francis

VERSION

AM (Accepted Manuscript)

LICENCE

CC BY-NC-ND 4.0

\section{REPOSITORY RECORD}

Lambert, John Peter, Paul R. Fleming, and Matthew W. Frost. 2019. "The Assessment of Coarse Granular Materials for Performance Based Pavement Foundation Design”. figshare. https://hdl.handle.net/2134/5087. 
This item was submitted to Loughborough's Institutional Repository (https://dspace.lboro.ac.uk/) by the author and is made available under the following Creative Commons Licence conditions.

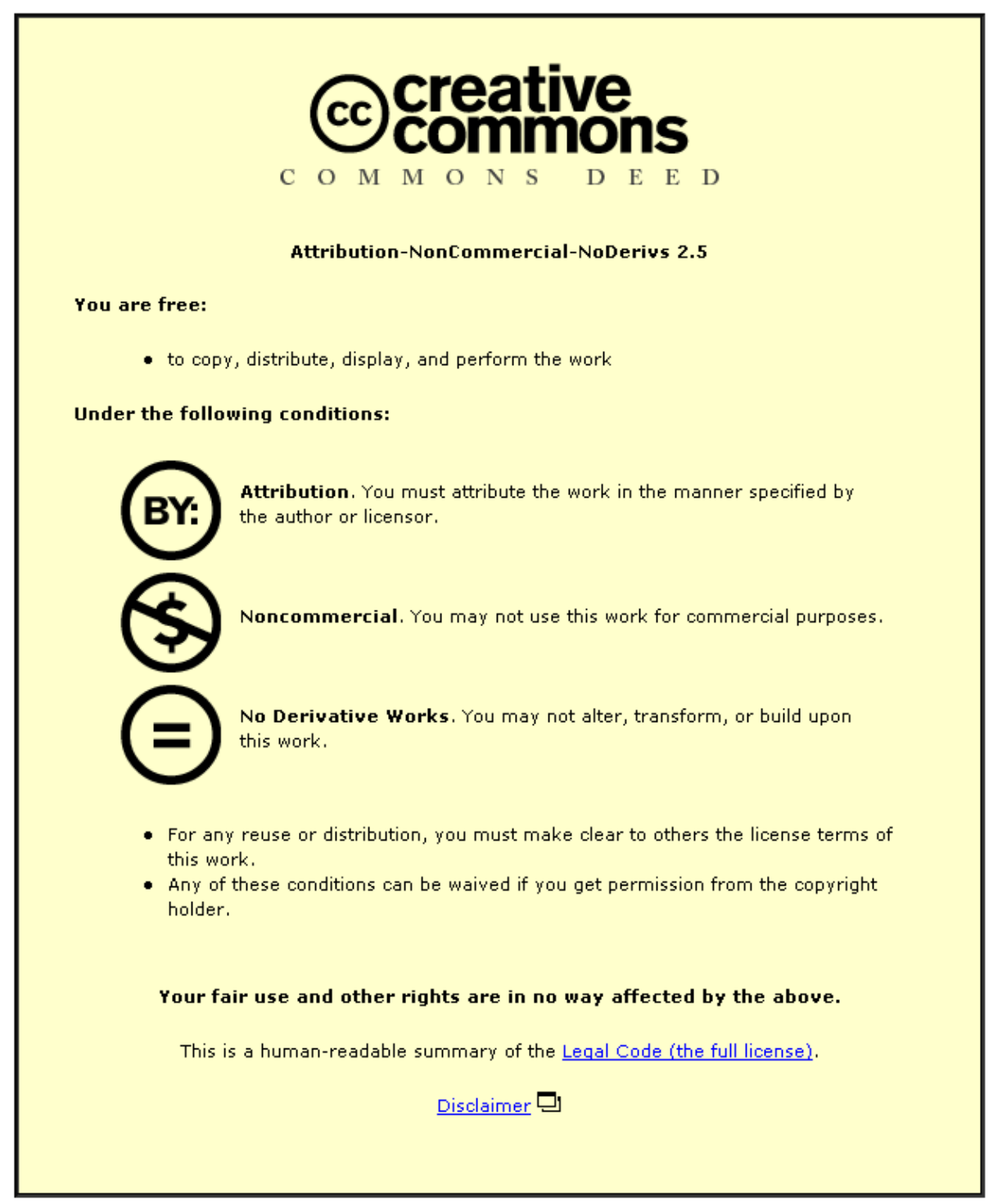

For the full text of this licence, please go to: http://creativecommons.org/licenses/by-nc-nd/2.5/ 
The assessment of coarse granular materials for performance based pavement

\section{foundation design}

J.P. Lambert ${ }^{1}$, P.R. Fleming ${ }^{2}$ and M.W. Frost ${ }^{2}$

1.

Scott Wilson

12 Regan Way

Chetwynd Business Park

Chilwell

Nottingham

NG9 6RZ

Email: John.Lambert@sscottwilson.com Telephone: +44 (0)1159077194

Fax: +44 (0)1159077001

2

Department of Civil and Building Engineering

Loughborough University

Loughborough

Leicestershire

LE11 3TU

United Kingdom

Email: P.R.Fleming@,lboro.ac.uk Telephone: +44 (0)1509 222616

Fax: +44 (0)1509223981

Email: M.W.Frost@,lboro.ac.uk Telephone: +44 (0)1509 228306

Fax: +44 (0)1509 223981

Word Count: 8363 words, 2 tables, 8 figures 


\begin{abstract}
The need to use more recycled and marginal materials in pavement foundations is encouraging moves towards performance based specifications. Such an approach needs data on the fundamental material parameters of stiffness and resistance to permanent deformation (strength) to allow analytical design and achieve comparable compliance testing on site. Whilst a number of laboratory and field tests to measure such performance exist, all have limitations relative to either the particle size of materials that can be tested and/or correlation between the laboratory and field derived data.
\end{abstract}

This paper presents the development of a large scale resiliently lined steel laboratory material box tests proposed for routine material assessment. The test utilises a Lightweight Deflectometer, similar to that proposed for field compliance testing to provide performance data from compacted large particle size granular materials. The system developed utilises a "soft" base condition to replicate typical subgrade stiffness and allows wetting and drying of materials to assess their environmental stability. The results show that such a test can simply provide suitable data for performance based design, but consideration needs to be given to the water content of materials, the time of testing after compaction, and the use of appropriate boundary conditions. These findings have both implications not only for the developed tests but for field compliance testing of pavement foundations.

Keywords Performance assessment; granular material; composite stiffness; dynamic plate test. 


\section{INTRODUCTION}

A performance based specification for road foundations is being developed in the UK, which requires the constructed foundation to achieve a series of target performance related parameters during construction (IAN73, 2006). These include a target stiffness, a minimum density, and a limit for permanent deformation. These parameters are required to allow construction of the foundation and the over lying structure whilst limiting the surface rutting caused by construction traffic, so as to protect the subgrade from possible damage. It is intended that by defining quantifiable and measurable performance parameters for design more flexibility can be afforded to the constructor in both the choice of construction methods and material. However, if a wider range of materials (including recycled materials) are allowed, a constructor will need some assurance of likely material performance before construction. Additionally, the use of performance related parameters for specifying the adequacy of the as built construction requires a good knowledge of these parameters with regard to expected material behaviour and the factors that influence their measurement.

The current research is aimed at investigating the laboratory performance of capping (coarse granular) materials to assess if their likely field performance can be adequately measured to assess material acceptability and performance for design. This paper describes the development of a large-scale laboratory box test that utilises a synthetic substrate to attempt to simulate appropriate field support conditions, to assess coarse granular materials prior to their use on site, with the aim of providing assurance of material performance for design. The background and the need for such a laboratory test is discussed. Data from the field are utilized to help develop and validate the laboratory test. 
The test sample preparation and testing methodologies are then described. A recent programme of work using the test to assess four materials, (a recycled crushed concrete, a natural, site-won mudstone, a site-won sandy gravel, and a quarried granodiorite aggregate) are presented. The test outcomes are then discussed, along with its relative merits and limitations and recommendations for further work are made.

\section{BACKGROUND}

\subsection{Pavement design and specification}

2.1.1 Pavement foundation function. A flexible pavement consists of two main sections, a foundation of unbound (granular) or stabilised layers overlying the subgrade and bound (structural) above. In UK pavement design the foundation comprises the subgrade, a capping layer (where required) and a sub-base layer (Figure 1). The primary functions of the foundation layers are to provide a working platform to build the structural layers by forming a regular surface, and to protect the exposed subgrade from the weather during construction. The foundation layers also function as a temporary haul road during installation of the layers above. The foundation is designed to distribute the loads applied by vehicles to the underlying subgrade, without distress to the foundation itself or subgrade. This must be achieved both during construction and during service in the longerterm. The vehicle loads on the foundation are highest during construction although of a limited number of applications, conversely during service the magnitude of loads at the foundation level are much lower, although there are many millions of applications. 
[Insert Figure 1 here]

2.1.3 Current design. The primary guidance for the design of flexible pavements is now found within the Design Manual for Roads and Bridges (HD 26/06, DMRB, 2006) which has recently been updated to include design options for Hydraulically Bound Material (HBM) bases. The new design method is based on TR615 (Nunn 2004) and this has been based on adaptation and updating (to include recent material advances) of the original guidance for the design of road pavements from Transport Research Laboratory Report LR1132 ( Powell et al, 1984). Within LR1132 the California Bearing Ratio (CBR) method forms the basis for pavement foundation design. The CBR provides an empirical indicator of subgrade material behaviour and has developed largely from experience and observations made on a number of experimental roads integrated into the public highway network. Therefore, design of capping and sub-base is governed by the in-situ condition of the subgrade. Capping and sub-base materials (currently described in the specification MCHW1, 2006) are designed to provide a CBR of at least $15 \%$ and $30 \%$ respectively at their top surface when placed and compacted in accordance with the specification to the thickness commensurate with the subgrade CBR (HD 25/94, DMRB, 1994).

While these critereia still apply within the revised guidance, the subgrade and foundation properties are now classified by a "long term" stiffness of the designed foundation broken into four foundation stiffness classes (Nunn 2004), which feed into an analytical design process. (However it has to be considered that any compliance measurement will be made of a short-term foundation stiffness prior to placement of the structural layers above.)

Despite the retention of the CBR test it does not directly measure the fundamental material properties that affect pavement performance and CBR can be inferred from index tests. 
The required parameters of material stiffness and resistance to permanent deformation (often indirectly inferred through a measure of material strength) are not measured in current design. In addition, current method specification philosophy does not necessarily make best use of materials, where as a performance-related specification does (Fleming and Frost, 2006).

2.1.4. Analytical foundation design. Analytical pavement design methods are used to predict the physical behaviour of materials under loading using their fundamental engineering properties. During their development the linear elastic models used must be calibrated against real pavement performance to ensure accurate predictions of (long-term) performance. The characterisation of materials in the models is via the properties of stiffness and strength (deformation resistance). Loads of a typical rolling wheel are theoretically applied to the structure and the resulting stresses and strains are computed at critical locations (Brown, 2002). Traditional UK analytical design for flexible pavements (in service) utilises critical values of maximum permissible vertical strain at the base of the granular layer (interface with subgrade) and maximum horizontal strain (tension) at the base of the bound layers (Figure 2) that are related to the probability of the pavement achieving its design life. Through an iterative process the thickness and elastic modulus (E) of each individual layer can be determined to ensure that the predicted stresses or strains are lower than the critical stresses and strains, although the more recent guidance in TRL 615 (Nunn, 2004) has removed the subgrade strain criteria. 
Adequate stiffness of the foundation/granular base layer is required to distribute the applied (vehicle related) stresses and to reduce the vertical strain at the top of the (cohesive) subgrade. Excessive strain at the top of the subgrade may lead to rutting, and these ruts may fill with water which will reduce the subgrade strength. In the short term, (i.e. during construction where the foundations are used as haul roads), the high directly applied stresses provide the most critical (failure) situation, although the number of load cycles is far lower than the in-service condition, typically 1000 standard axles is used for foundation design (Powell et al, 1984).

Analytical based design has become more feasible as computers have become more powerful and the measurement of the in-situ behaviour of pavement foundation materials has become more routine (e.g. using dynamic plate test apparatus). The analytical process also allows the use of fundamental material properties to optimise the design of a 'fit for purpose foundation', however it is important to still account for some risk within the design and apply factors of safety. A bespoke foundation specification is required to complement the analytical design process to ensure the best use of available resources for construction, coupled with a suite of suitable test methods to both design and validate the foundation performance.

2.1.5 Performance specification. In the UK a performance based specification for road foundations has been developed (IAN 73, 2006). It requires the road foundation to achieve a series of target performance related parameters during construction. These include a target composite stiffness, (measured by a dynamic plate test) and a minimum density. Measurements of composite stiffness are made both on the formation layers and foundation surface, density is measured on the upper compacted layers only. However if a wider range 
of new or recycled materials are to be allowed, a constructor will need some assurance of adequate material performance before construction. The use of performance related parameters for specifying the adequacy of the 'as built' construction requires a good knowledge of these parameters with regard to both expected material behaviour and the influences on their measurement. Full-scale field trial sections are currently used for large schemes to assure the suitability of materials. However, it is still prudent to develop a routine, economical, laboratory-scale means to assess the performance and suitability of the foundation materials before full-scale field trials.

\subsection{Granular material behaviour}

Unbound granular materials show a relatively complex elastoplastic behaviour when subjected to repeated cycles of loading such as generated by moving traffic (Lekarp et al, 2000). The effect of a single cycle of load is to cause both elastic strain and permanent strain. The magnitude of elastic strain depends upon the elastic modulus and the amount of permanent strain depends on the proximity of the applied stress to the failure stress, and accumulates under repeated cycles.

A material's elastic stiffness determines its load spreading capability, which reduces the magnitude of surface applied stress transferred to the layers below. Several physical material properties that affect the resilient response of granular materials include; material type, particle size, grading, water content, surface characteristics (angularity and roughness), the compacted density and applied stress level (Hicks and Monismith, 1971 ). A principal influencing factor is the stress level, the K-theta model appears widely accepted for analysis of the nonlinearity of the elastic modulus of granular materials and is 
regarded as an adequate simplification for analytical design purposes (Lekarp et al, 2000). The extent to which the modulus varies with stress is determined by the coefficient $\mathrm{k}_{2}$ of the K-theta model (Boyce, 1980) which states;

$\mathrm{Mr}=\mathrm{k}_{1} \theta^{\mathrm{k}_{2}}$

Where:- $\quad \begin{array}{ll}\mathrm{Mr} & =\text { Resilient Modulus }(\mathrm{MPa}) \\ \theta & =\text { bulk stress }(\mathrm{MPa}) \\ \mathrm{k}_{1} \text { and } \mathrm{k}_{2} & =\text { material constants }\end{array}$

The parameters $\mathrm{k}_{1}$ and $\mathrm{k}_{2}$ are usually derived from triaxial tests, however, Tong and Baus (2005) found through sensitivity analysis that it was not reliable to backcalculate both $\mathrm{k}_{1}$ and $\mathrm{k}_{2}$ values simultaneously. The degree of saturation, sample compactive effort, and soil gradation all had a significant effect on $\mathrm{k}_{1}$ values, whereas these factors had minor or no impact on $\mathrm{k}_{2}$ values. This non-linear stress-strain behaviour has significant implications for field assessment test methods and protocols for the evaluation and selection of the appropriate value of elastic modulus for any design process.

Permanent deformation (rutting) in granular materials is caused by shear within the material itself, either due to insufficient inherent strength or due to high stress within a weak underlying layer. Factors affecting permanent deformation include the applied stress level, number of cycles, particle shape, grading, angularity and roughness, and the previous load history (Fleming and Rogers, 1995). The prediction of permanent deformation behaviour for design is difficult, and in general a measurement of strength has proven a useful indicator of the propensity for rutting in a material. 


\subsection{Laboratory assessment techniques}

A number of laboratory element tests already exist that can be used to assess the performance properties of granular materials. These include the Triaxial Test, the K Mould (Semmelink and de Beer, 1995) and the recently developed Springbox (Edwards et al., 2004). However, in these tests the maximum particle size is generally restricted to $20 \mathrm{~mm}$, (or in the case of the Springbox, 40mm). For larger particle sizes the test samples need to be bigger and become cumbersome and more difficult to handle and prepare (Sweere, 1990). In the UK capping materials have a particle size limit of $125 \mathrm{~mm}$, and a maximum allowable test particle size of $40 \mathrm{~mm}$ potentially excludes $25 \%$ of the sample (by mass) of a Class 6F1 (Fine) capping and as much as 55\% of a Class 6F2 (coarse) capping (MCHW1, 2006) (Figure 3 shows the grading limits).

[Insert Figure 3 here]

In addition, the methodology of elastic modulus measurement in these tests makes direct comparison of the laboratory results to field measurements (using the portable dynamic plate test devices) difficult. These element test methods are thus considered unsuitable to routinely assess the expected field behaviour of the very coarse granular capping materials.

To assess very coarse aggregates it is considered necessary to use relatively large test moulds that can contain a representative size sample and limit sample/mould boundary influences. It has been suggested that an aspect ratio of sample to particle size of ten is 
appropriate as a minimum (Lekarp et al. 2000). A very large rigid mould was used by Tingle and Jersey (2005) to evaluate cyclic plate load testing of unbound aggregate roads. A $1.83 \mathrm{~m}^{2}$ by $1.37 \mathrm{~m}$ deep reinforced steel 'containment vessel' was used into which a $0.8 \mathrm{~m}$ thick compacted clay subgrade and $0.36 \mathrm{~m}$ thick compacted crushed limestone base course was installed as a foundation sample to be compacted and tested using a pneumatic compactor. Tong and Baus (2005) performed full-scale cyclic and static laboratory plate loading tests in a large $4 \mathrm{~m}^{2}$ by $3 \mathrm{~m}$ deep test pit to investigate the mechanical properties of unbound granular materials. However, the very large volume of sample and the use of clay substrates restricted the practicality of this approach for a routine and economical laboratory assessment test.

\subsection{In-situ assessment techniques}

The most direct and arguably accurate method of measuring material performance in a road foundation is by using a full-scale foundation trial, including in-situ measurements and controlled trafficking. This may be appropriate for larger construction schemes for full design validation and material assessment. However a laboratory test is still desirable for preliminary material selection and assessment of behaviour (under controlled conditions) and provides much greater economy relative to fieldwork.

Many stiffness measuring devices are in existence, such as the static plate bearing test and more contemporary portable dynamic plate tests. The portable devices are considered more appropriate for commercial use as they are quicker and better recreate the transient nature of a wheel load. The portable devices typically measure (indirectly via a velocity transducer) a single deflection on the centre of the bearing plate (or on the ground through a hole in the plate). The measurement is termed a 'composite' stiffness ( $E_{\text {comp, }}$ 
Equation 2), because the measured deflection may relate to the influence of more than one layer of material (Fleming et al. 2000). In addition, the term 'stiffness' and not elastic modulus is usually used as the test measures the maximum deflection under load, and may not be truly elastic. Based on Boussinesq elastic half space theory the stiffness measured is calculated from the following equation.

$\mathrm{E}_{\mathrm{comp}}=\frac{\mathrm{A} \cdot \mathrm{P} \cdot \mathrm{r}\left(1-v^{2}\right)}{\mathrm{d}}(\mathrm{MPa})$

$$
\begin{aligned}
& \text { Where:- } \quad \begin{array}{cl}
\mathrm{A} & =\text { plate rigidity factor }(\pi / 2 \text { for rigid plate }) \\
\mathrm{P} & =\text { applied stress }(\mathrm{kPa}) \\
\mathrm{r} & =\text { plate radius }(\mathrm{m}) \\
v & =\text { Poisson's ratio } \\
\mathrm{d} & =\text { deflection }(\mathrm{mm})
\end{array}
\end{aligned}
$$

The portable devices (with a 10kg falling mass) can apply a stress of up to $150 \mathrm{kPa}$ over a period of approximately 20 milliseconds, via a 300mm diameter bearing plate. The depth of significant additional stress $(10 \%$ of applied stress $)$ is expected to be approximately 1.5 to 2 times the bearing plate diameter (i.e. $450 \mathrm{~mm}$ maximum for a 300 plate). Thus in many construction cases the composite stiffness measured will be a combination of the stiffness response of more than one material layer, but potentially not the full pavement. A full review of such devices is given elsewhere (Fleming et al. 2002).

The in-situ strength of foundation materials can be routinely assessed using the Dynamic Cone Penetrometer (DCP), though difficulties can occur in strong and very 
coarse materials due to the low (manual) impact energy and small cone size. However, the DCP is considered to be a useful and simple-to-use portable tool for discriminating between materials and for identifying changes in any one material's strength (Fleming et al, 2003). Another useful indicator of strength is the Clegg Impact Hammer, which is also simple and portable. It has been used to assess and control the compaction of granular soils in the field (Kim et al. 2005). It measures the maximum deceleration of a $4.5 \mathrm{~kg}, 50 \mathrm{~mm}$ diameter cylindrical hammer, falling through $450 \mathrm{~mm}$ to impact the surface of the material under test. The Impact Value (IV) reflects changes in the near-surface strength of the compacted material and has traditionally been used in the UK in lieu of a direct density measuring device, to compare between materials prepared in the laboratory and field, especially for the reinstatement of utilities trenches.

\subsection{Field trials}

During the research and development of a draft performance specification (Fleming et al, 2003) several site trials were conducted, comprising in-situ field measurements to assess the proposed specification compliance test methods and for design validation. A brief summary of some of the data for materials similar to those tested in the laboratory in this research are presented in Table 1, (including assessment of stiffness, shear strength (via DCP), and density). The field data shown in the table were from both live construction sites and specifically constructed field trials.

[Insert Table 1 here] 
From Table 1 it can be seen that the subgrades encountered in the trials covered a range of materials, from clays through to weak rocks and their stiffness varied significantly, particularly the stiffness of the clay subgrades. When conditions were dry and warm, the subgrade stiffnesses were often very high. In these cases, the composite stiffness was often higher on the subgrade than on the placed and compacted capping layer above.

Trafficking trials were also carried out at most of these sites to assess their resistance to permanent deformation. These trials demonstrated the importance of the interaction of layers in the development of rutting, especially for unbound capping layers compacted onto clay subgrades whereby, if the clay deformed, dilation of the overlying granular material were possible and deterioration (rutting) rapidly occurred thereafter (Fleming and Rogers, 1994). In one trial several materials were constructed above both a clay subgrade and a concrete slab that had been cast in a section of the clay. A $20 \mathrm{~mm}$ thick rubber sheet was installed above the concrete and the capping then placed on top. The stiffness data in Table 1 (Site 1, Sections 1.2-1.5) show that the composite stiffness was greatly improved above the artificial substrate (material 1.5), however the capping density measurements did not show a significant difference (it must be noted that the compactive effort was varied and Sections 1.2, 1.3 and 1.4 represent 'poor', 'medium' and 'good' compaction on the clay subgrade). The DCP measurements, however, were more sensitive to the compactive effort and correlated well with the resistance to permanent deformation that was observed (above the artificial substrate (Section 1.5). For example only a $3 \mathrm{~mm}$ rut was observed after 1000 passes of a construction vehicle compared to $153 \mathrm{~mm}$ rut after 100 passes above the clay ( Section 1.4)). However, the subgrade was very soft in this location and the granular sub-base layer was deliberately under-designed to ensure 
deformation occurred. However, Fleming and Rogers (1994) with this work demonstrated the value of field trials, in comparison to laboratory element tests to determine ruttability, and demonstrate a good correlation between rutting and strength measurement.

This previous research showed that the composite stiffness and rutting behaviour is a complex function of both the material's intrinsic properties and the interaction of the layers, particularly the depth of the zone of influence of the loading (of the wheel/dynamic plate test). The thickness of the unbound layers above the subgrade, and their intrinsic stiffness, are clearly two important factors in the distribution of stress and hence strains in the constructed system. Thus the progression of changes of composite stiffness and strength with the construction of the foundation layers is a key area of interest for this study.

Field data demonstrates a large range of composite stiffnesses for the granular capping materials, and sub-base layers, (Fleming et al., 2000), however the typical range was $40-142 \mathrm{MPa}$ with a large scatter at any one site (10-35\% Coefficient of Variance). Therefore minimum 'acceptable' site composite target stiffness values were determined from this and theoretical analysis, and subsequently included in the draft performance specification (IAN 73, 2006). These values were set to demonstrate both good material integrity but also to produce a suitably stiff platform upon which to compact the next designed layers.

\section{Test philosophy}

From the above it is thus clear that any laboratory test developed to measure capping stiffness to feed into the foundation design process must aim to provide comparable 
performance measurements between the laboratory and the field, and able to assess the performance parameters of stiffness and strength. A large test mould is deemed necessary to enable a representative sample of material with a particle size up to $125 \mathrm{~mm}$ to be evaluated. The test mould should be sufficiently rigid for the sample to be adequately compacted in layers to match field achieved material compaction and density. However, it must have appropriate boundary conditions to provide similar levels of support to that expected of subgrades in the field. Additionally, an ability to simulate changes in water content and permit drainage is desirable to evaluate changes in environmental effects. Finally, the test developed has to ideally be practical, relatively simple, routine and must be able to be implemented commercially. Therefore, a large stiff test mould into which materials can be compacted is proposed. Measurements of stiffness and strength should be made with the same devices that are suggested for performance evaluation in the field.

In order to ensure compatibility between the laboratory test and field performance it is essential to control the material, the compaction methodology and the method of measuring the performance. Therefore, the material should have representative particle density, grading and be of the same mineral type, requiring careful sampling from any stockpile. The confinement and stress state of the sample affect composite stiffness and strength, thus it to must be comparable between the assessment test and field (as far a practicable). Therefore the compacted density, water content and method of compaction of samples must be controlled.

When comparing data between laboratory and field the confinement offered by a laboratory mould and the composite stiffness of the mould base should be comparable. The more comparable these factors between the laboratory and the field the more comparable the composite stiffness and strength measured in the test. 


\section{METHODOLOGY}

\subsection{Test mould}

A large rigid steel mould of internal dimensions $1 \mathrm{~m} \times 1 \mathrm{~m} \times 0.5 \mathrm{~m}$ deep was constructed, (Figure 4). It comprised controlled drainage points evenly spread about its base, to allow wetting and drying of the sample and to facilitate drainage.

\section{[Insert Figure 4 here]}

A synthetic substrate layer was used within the mould to create a 'soft' base stiffness condition. The stiffness measured directly on this layer was intended to be similar to the stiffness of a typical UK subgrade. A synthetic rubber sheet, similar to that used by Fleming and Rogers, (1994), of $0.95 \mathrm{~m} \times 0.95 \mathrm{~m}$ by $20 \mathrm{~mm}$ thick was placed in the base of the mould. The synthetic rubber had a surface hardness of between 40-50 IRHD (International Rubber Hardness Degrees) and a density of $1.1 \mathrm{Mg} / \mathrm{m}^{3}$. A thin drainage layer was installed between the base of the mould and the rubber to facilitate through drainage of the sample. A 5mm thick rigid plastic geo-drain fitted with geotextile filter on both sides was used. The 'soft' base conditions composite stiffness (within the mould) was approximately $40 \mathrm{MPa}$ measured by a dynamic plate test. A 'stiff' base condition was provided by removing the rubber and geo-drain, thus using the mould base alone, and the stiff base stiffness was in excess of 200MPa. 


\subsection{Material used}

Four material samples were tested in the laboratory, they were selected to represent marginal, recycled and standard unbound granular materials typically used in pavement foundations, (a mudstone, a crushed concrete and a site won sandy gravel and crushed rock respectively).

The recycled crushed concrete assessed was classified as a 6F1 capping (MCHW1, 2006) (Figure 3) with an optimum water content (owc) of $12 \%$ and maximum dry density of $1.95 \mathrm{Mg} / \mathrm{m}^{3}$. The mudstone assessed was classified as a $6 \mathrm{~F} 2$ capping and was found to have an owc of $8 \%$ and maximum dry density of $1.95 \mathrm{Mg} / \mathrm{m}^{3}$. The third material tested was classified as a sandy gravel, with an owc of $7 \%$ and maximum dry density of $2.18 \mathrm{Mg} / \mathrm{m}^{3}$. This sample predominantly fell within the 6F2 capping classification. The crushed rock material utilized was a good quality type 1 sub-base (granodiorite) from a local quarry, with an owc of $4.5 \%$ and maximum dry density of $2.2 \mathrm{Mg} / \mathrm{m}^{3}$. This latter material was used as a standard to provide a benchmark against which to assess the other materials.

\subsection{Laboratory sample preparation}

The optimum water content and maximum dry density for the materials tested was derived from a standard laboratory compaction test (BS 5835, Part 1, 1980). A large capacity mixer was used to facilitate wetting or drying of samples to optimum water content prior to installation. The materials were then installed and compacted in four layers of $100 \mathrm{~mm}$ thickness. Compaction was performed using a 56kg electric vibrating rammer, with four passes for each layer, (in accordance with the standard UK specification for compaction- 
MCHW1, 2006) and gave values of density in the mould similar to those obtained in standard proctor compaction tests.

\subsection{Stiffness and strength measurement}

The composite stiffness $\left(\mathrm{E}_{\mathrm{comp}}\right)$ was measured using the dynamic plate $(300 \mathrm{~mm}$ diameter bearing plate) test at five positions around the surface of each layer as the layers were built up. One test was located at the centre of the mould, the other four test locations were placed towards the corners of the mould with the centre of the bearing plate approximately 250mm from the side walls (positions 1 to 4, Figure 5). Repeat $\mathrm{E}_{\text {comp }}$ test were made at the five points 24 hours later. Impact Hammer tests were performed, with three tests at each of the five locations. The DCP test was then performed, (no closer than $250 \mathrm{~mm}$ from the mould sides) this test process was repeated on each layer after installation. The order in which measurements were made with the various devices was important to minimise sample disturbance, and so the stiffness measurements were made before the intrusive strength readings.

[Insert Figure 5 here]

The dynamic plate test was performed using a 300mm diameter plate with the geophone contacting the material surface. The device was positioned to ensure good surface contact and three pre-compaction drops at $100 \mathrm{kPa}$ stress were applied to seat the plate firmly. Four further drops were then applied, one at $40 \mathrm{kPa}$, one at $70 \mathrm{kPa}$ and two at 
$100 \mathrm{kPa}$ contact stresses. The average stiffness from the last two drops was used to express the test result for composite stiffness.

The DCP test was performed to BS 5930 (1999). The top and bottom 50mm of penetration were ignored in the data interpretation due to low confinement at the surface and the influence of the mould base on the test. The Impact Hammer test was performed and interpreted using the manufacturers standard (Trevor Deakin Consultants LTD, 1990), five repeated impacts were carried out, and the fifth value reported.

\subsection{Laboratory tests performed}

The four materials were evaluated (the data are presented in Table 2) and the suitability of the test mould assessed as follows. Initially, different base boundary conditions were assessed; a test was performed where the samples were compacted directly onto the 'rigid' base of the mould. In the second test the synthetic subgrade was placed in the mould to provide a 'soft' base condition. The moisture susceptibility of the capping was assessed by wetting it to saturation from the surface, and later allowing drainage through the base, (as might be expected during poor weather on site). The quantity of water added to achieve full saturation was based on an estimation of air void content from the density and compacted original water content data. The composite stiffness and strength were remeasured upon saturation and then again after a controlled period of drainage (measurements at 24hour intervals). Repeat cycles of wetting and drainage were also performed.

\subsection{Field data collection}


For comparison to the laboratory data selected data from the field measurements at live sites and field trials are shown in Table 1, for similar material types, grading, thickness and density to those assessed in this work. However, live site data there is always the problem of lack of control and the exact time since compaction, amount of construction traffic and water content at the test locations was generally unknown. The same test measurement methods and analyses were used for direct comparison to the laboratory test.

\section{RESULTS}

\subsection{Field and laboratory comparison}

5.1.1. Field data. In general, the field data in Table 1 showed the magnitude of composite stiffness did not necessarily increase upon installation of the capping layer above that of the subgrade, however the scatter of the composite stiffnesses measured did decrease at any one site (e.g. 12-57MPa down to 25-48MPa, Site 5, Sections 5.1 and 5.2 respectively, Table 1). DCP data inferred as CBR showed a tendency to increase with increase in material thickness possibly due to greater confinement (Table 1), as did the composite stiffness.

Material type (i.e. mineralogy and grading) also appeared to have a significant effect on the strength and composite stiffness measured on site. The 'good quality' crushed rock used in the Type 1 sample was less variable in performance compared to the other samples. 
5.1.2. Laboratory data. The composite stiffness increased as the layer thickness increased for the 'soft' base condition (Table 2). The strength also increased with depth due to an increase in confinement resulting from the increased thickness.

The range of strength and composite stiffness values recorded in the laboratory appeared to vary between the different material types and material gradings, this became more significant once the sample thickness increased above $300-400 \mathrm{~mm}$.

It was observed that the composite stiffness increased for both the sandy gravel and granodiorite materials after allowing a rest period between installation and assessment. A rest period of approximately 24 hours was thereafter adopted between an initial test and a repeat test for the sandy gravel and granodiorite materials

[Insert Table 2 here]

5.1.3. Comparison of field to laboratory data. From the field data presented in Table 1 the subgrade composite stiffness ranged from between 12-57MPa (Section 5.1) for a soft/firm clay to $37-65 \mathrm{MPa}$ (Section 4.1) for a mudstone capping. In the laboratory the composite stiffness measured on the synthetic substrate was approximately $40 \mathrm{MPa}$.

The granodiorite sample achieved a relative dry density in the laboratory of between $120-130 \%$ of that measured in-situ in the field (possibly due to slightly different gradings between the material tested on site and in the laboratory and due to difference in the compactive effort experienced in the field). The mudstone sample achieved a relative dry density in the laboratory of between $83-98 \%$ to that in the field. The crushed concrete achieved a relative dry density of between $86-98 \%$ in the laboratory compared to the field. No field compaction data was available for the sandy gravel. 
Most of the laboratory assessed composite stiffness results were slightly lower than the site data at the same layer thickness (Sites 5-7, Table 1). However, the strength of the compacted materials appeared to be of similar magnitude between field and the laboratory (comparing data at the similar layer thicknesses).

\subsection{Laboratory boundary effect}

It is considered that the base stiffness affected the composite stiffness and strength assessed for the sandy gravel sample. On the 'stiff' base condition (200MPa) the material composite stiffness decreased as layer thickness increased (Figure 6a). On the 'soft' base condition (40MPa), composite stiffness increased as layer thickness increased (Figure 6b), and it was observed that the deflections at the centre position on the first layer were too large $(>2 \mathrm{~mm})$ so out of range of the plate devices. At full thickness, the CBR assessed was $10 \%$ lower for the 'soft' base condition compared with the stiff base condition

\section{[Insert Figure 6 here]}

Composite stiffness data for the laboratory samples showed consistently lower stiffnesses measured at centre position in the mould (Figure 6a and 6b). Clearly the rigid walls of the mould were having some effect for the outer measurement positions. No appreciable effect of this nature was shown in the DCP strength data, as it is thought this affects a smaller radial zone of material under test.

\subsection{Stress sensitivity}


The stress dependency of the stiffness of the granular materials was investigated from the data when varying the dynamic plate test contact stresses (ranging from $40 \mathrm{kPa}$ up to $100 \mathrm{kPa}$ ). Lines of best fit for applied stress against composite stiffness were used to derive stress/strain constants for the k-theta model.

The $\mathrm{k}_{2}$ values calculated for the sandy gravel ('soft' base condition) ranged from 0 to 0.44 and for the granodiorite ('soft' base condition) from 0.41 up to 0.86 .

\subsection{Wetting and drying}

Upon wetting, the composite stiffness decreased for the compacted sandy gravel (Figure 7). The DCP strength was not significantly affected by this, other than near the surface. After drying the composite stiffness increased almost three fold. The strength also increased $50 \%$ to $300 \%$ after drying. The same trends were observed on the second cycle after wetting.

[Insert Figure 7 here]

\section{Discussion}

\subsection{Field and laboratory comparison}


The composite stiffness of the laboratory mould 'soft' base condition was within the range found in the field, and for the same thickness of placed materials in the mould the composite stiffness measured in the laboratory was similar to that in the field.

It was clear that there was some effect of allowing the sample to 'rest' before testing took place in the laboratory, with the sandy gravel being most sensitive - (this observation was reinforced by some parallel test work in another novel piece of test equipment (the Springbox, Edwards et al., 2004). The stiffness of the materials increased by up to 2 times, 24 hours after compaction.

Although in-situ suction measurements were not made, an equalization of pore water pressure in the material is believed to cause this effect. This clearly has implications in the timing of any assessment testing both in the laboratory and in the field following compaction.

\subsection{Laboratory boundary effect}

For the 'stiff' base condition (Figure 6b) the relatively high stiffness of the base seemed to mask the stiffness of the material in the test (the stiffness ratio between the capping and the base is clearly high). With the 'soft' base condition, the ratio of $\mathrm{E}_{\text {comp }}$ top of capping to substrate was approximately 3:1 (i.e. $120 \mathrm{MPa}$ versus $40 \mathrm{MPa}$ ), which accords with Powell et al, (1984) who expressed a ratio of 2:1 for safe design. Elastic theory states that the effect of the base stiffness on the composite stiffness should decrease once the sample thickness reaches the depth of the stress bulb, i.e. $450 \mathrm{~mm}$, or 1.5 times the test plate diameter. The stiffness ratio between the capping and 'soft' base condition is much less than the stiffness ratio between the capping and 'stiff' base condition and it is considered 
that the 'soft' base condition is more representative of field support conditions. However, it has to be considered that the (elastic) synthetic substrate may have affected the capping layer response during compaction of the base layer, however, it is more difficult to ascertain these effects however. The compacted material densities achieved were very similar between the two substrate conditions assessed which perhaps demonstrates again the uncertainty of density as a performance parameter. However, more confinement may have been afforded after compaction on the soft (resilient) base condition by allowing more particle reorientation during compaction. Based on these findings the 'soft' base condition was chosen as the preferred condition as it better reproduced field support conditions and expected behaviour in general.

The side wall may reduce the amount of vertical deflection sustained by adjacent materials by offering frictional resistance (in the vertical direction) and also permits less horizontal deflection by providing greater (stiffer) confinement. Therefore, it is considered that tests at positions 1-4 around the mould edge may overestimate the sample composite stiffness somewhat. The test stress bulb theoretically extends horizontally by a distance approximately 0.9 times the plate diameter from the centre-line of the plate, thus for a $300 \mathrm{~mm}$ plate it extends $270 \mathrm{~mm}$, therefore the side wall is expected to have some influence if a test is performed closer than this to the side. The centre position is not considered to be significantly affected by the boundary walls.

\subsection{Laboratory stress sensitivity}

The range of $\mathrm{k}_{2}$ values calculated for the sandy gravel and granodiorite generally agree with the range quoted by Boyce (1980) of between 0.4 to 0.8 for granular materials. The 
sandy gravel and granodiorite stiffness values are both stress sensitive, therefore the magnitude of stress applied during testing is clearly important. Inclusion of stress dependency is important in foundation thickness design for achieving a target composite value in the field, and some assessment of this is recommended.

\subsection{Wetting and drying}

The sandy gravel material was clearly moisture susceptible (Figure 7). The water content profile for the layers of the 'as installed' material after the second cycle of drying (when the material could be excavated and the water content assessed) is presented in Figure 8. Figure 8 clearly shows that during the drying phase (approximately eight days) the sample dries preferentially from the top, and hence that the greatest suctions occur here, (the samples were open to drainage and surface drying effects).

Figures 7 and 8, combined, demonstrate the high sensitivity of the sandy gravel behaviour to wetting and drying. This is an important issue for the field, for measuring and achieving performance targets. The performance measured on site should perhaps only be considered a 'snapshot' relating to the stress state in the material at the time of testing and should ideally be assessed just before construction of the next layer (and proper protection from excessive water ingress be put in place).

\section{[INSERT FIGURE 8 HERE]}

\subsection{Summary}


The findings of this research provided preliminary validation of the assessment test developed. Comparison between field and laboratory results was considered a suitable means to provide this preliminary validation, and the conditions between the laboratory and the field were comparable.

\section{CONCLUSIONS}

A routine large-scale laboratory test for the assessment of coarse granular capping materials has been developed and test data presented. The following conclusions are drawn from this work.

- It is considered difficult to assess the expected field behaviour of aggregates with coarse particles in conventional element tests in the laboratory, and there is a need for a relatively large-scale routine test method which can accommodate such large particle sizes.

- The test methodology developed can utilise the same equipment used in the field for direct comparison of composite stiffness and (indirect) strength behaviour.

- The 'soft' base (boundary) condition was effective for compaction of the granular materials and was considered more representative of the field subgrade condition than the 'stiff' base condition.

- The inclusion of a 'rest' period after compaction was shown to have a significant effect on the measured composite stiffness generally showing an improvement in stiffness after 24 hours.

- Boundary effects were shown to affect the composite stiffness measured with the plate test, most significantly at the peripheral test positions in comparison to the centre position. 
- The dynamic plate test measured stress sensitive behaviour for the granular materials. Therefore there is a need to ensure testing at comparable magnitudes of stress, for the laboratory and field

- The sandy gravel tested was found to be moisture susceptible, and was able to maintain negative pore water pressures that had a large effect on both its stiffness and strength behaviour.

- Changes in water content post installation have important consequences for achieving site target values in a performance specification.

- Composite stiffness measurements were found to be sensitive to the proximity of the mould boundary, type of base support, applied (normal) stress, plate diameter, as well as factors such as material type and material wc.

- The assessment test provides a useful tool for industry which indicates a materials potential composite stiffness, strength and moisture susceptibility to provide data to be used in design and the field to allow an appreciation of likely performance.

\section{FUTURE WORK}

A further programme of controlled field trials and laboratory tests are proposed to extend the database of results and provide further validation of the test methodology, that will include assessment of the wetting and drying behaviour of the materials in-situ.

\section{ACKNOWLEDGEMENTS}


The research was undertaken as part of the engineering doctorate (EngD) scheme at Loughborough University funded by the EPSRC and the UK Highways Agency. The opinions expressed are solely those of the authors and not necessarily those of the UK Highways Agency.

\section{References}

Boyce, J.R. A Non-linear Model for the Elastic Behavior of Granular Materials Under Repeated Loading. International Symposium on Soils Under Cyclic and Transient Loading, Swansea, 1980, pp. 285-294.

Brown, A., Practical applications of analytical pavement design, Performance Infrastructure, Transport Research Laboratory Seminar, Crowthorne, Berkshire, UK. 2002.

British Standards Institution. Testing of Aggregates. Compactability tests for graded aggregates. London, BS 5835-1, British Standards Institution, 1980.

British Standards Institution. Code of practice for site investigation. London, BS 5930-1, British Standards Institution, 1999.

DMRB, Design Manual For Roads and Bridges, Volume 7, Section 2 Pavement Design and Construction, Part 2, HD 25/94 Foundations, HMSO, London. UK. 1994. 
DMRB, Design Manual For Roads and Bridges, Volume 7, Section 2 Pavement Design and Construction, Part 3, HD 26/01 Pavement Design, HMSO, London. UK. 2001.

Edwards, J.P., N.H. Thom, and P.R. Fleming. Development of a simplified test for unbound aggregates and weak hydraulically bound materials utilising the NAT, Proceedings of the $6^{\text {th }}$ International Symposium on Pavements Unbound, Nottingham, 2004, p. 3-11.

Fleming, P.R. and M.W. Frost. Sustainable earthworks specifications for transport infrastructure, $85^{\text {th }}$ Transportation Research Board meeting, National Research Council, Washington., D.C., USA, 2006, [CD-ROM].

Fleming, P.R., M.W. Frost, and C.D.F. Rogers. A comparison of devices for measuring stiffness in-situ, Proceedings of Fifth International Conference on Unbound Aggregates in Roads, Nottingham, July 2000, pp 193-200.

Fleming, P.R., J.P. Lambert, M.W. Frost, and C.D.F. Rogers., 2002. In-situ assessment of stiffness modulus for highway foundations during construction, CD-ROM, 9th International Conference on Asphalt Pavements, Copenhagen, Denmark, pp. 12.

Fleming, P.R. and C.D.F. Rogers. Assessment of Permanent Deformation Characteristics of Four Granular Pavement Foundation Materials In Situ, Proceedings of Fourth International Conference on Bearing Capacity of Roads and Airfields, 2, Minneapolis, USA, July 1994, pp 967-988. 
Fleming, P.R. and C.D.F. Rogers. Assessment of Pavement Foundations During Construction, Transport, The Proceedings of the Institution of Civil Engineers , 111(2), 1995, pp 105-115.

Fleming, P.R., C.D.F. Rogers, N.H. Thom, and M.W. Frost. A performance specification for pavement foundations. Transportation Geotechnics, Proceedings of the EMGG Transportation Geotechnics Symposium (ed M.W. Frost et al). Thomas Telford Publications, London, 2003, pp. 161 to 176.

Hicks, R.G. and C.L. Monismith. Factors Influencing the Resilient Response of Granular Materials. Highway Research Report 345. Highways Research Board, 1971, pp. 15-31.

Interim Advice Note 73/06. Guidance for road pavement foundations, Design manual for roads and bridges. Volume 7, Section 2, Part 3, Draft HD25. 2006, HMSO, London, UK

Kim, D., N.Z. Siddiki, K. Sommer, and W. E. Jackson (II). Field Compaction Evaluation with DCPT, Clegg Hammer, and Nuclear Gauge Test, Proceeding of the 84th Annual Meeting of the Transportation Research Board, Paper 05-1440, Washington, DC, 2005, pp 1-22.

Lekarp, F., U. Isacsson and A. Dawson. State of the Art. 1: Resilient Response of Unbound Aggregates, Journal of Transportation Engineering. ASCE, 2000, pp. 66-75. 
Manual of Contract Documents for Highway Works, Specification for Highway Works. Vol. 1, HMSO, London, UK. 2006.

Nunn M.E. : Development of a More Versatile Approach to Flexible and Flexible Composite Pavement Design. Transport Research Laboroatory (TRL) Report 615 Crowthorne, Berkshire, UK, 2004.

Powell, W.D., J.F. Potter, H.C. Mayhew, and M.E. Nunn. The Structural Design of Bituminous Roads (LR 1132). Transport Research Laboratory, 1984, Crowthome Berkshire, UK.

Semmelink, C.J. and M. de Beer. Rapid Determination of Elastic and Shear Properties of Road-building Materials with the K-mould. Proceedings of Fourth International Conference on Unbound Aggregates in Roads, 1995, pp. 151-161.

Sweere, G.T.H. Unbound granular bases for roads. Proceedings of Fourth International Ph.D Thesis, Delft University of Technology, Delft, The Netherlands, 1990.

Tingle, J.S. and S.R. Jersey. Cyclic Plate Load Testing of Geosynthetic-Reinforced Unbound Aggregate Roads, Proceeding of the 84th Annual Meeting of the Transportation Research Board, Paper 05-1935, Washington, DC, 2005, pp 1-24.

Tong, L. and R.L. Baus. Nonlinear Parameters for Granular Base Materials from Plate Tests. Journal of Geotechnical and Geo-environmental Engineering, ASCE, July 2005, pp. 907-913. 
Trevor Deakin Consultants LTD, Clegg Impact Soil Tester, 1990. 


\section{List of tables}

TABLE 1 Material test data from field trials in the United Kingdom.

TABLE 2 Material test data assessed in the laboratory mould using the soft base condition.

\section{List of Figures}

FIGURE 1 Key design considerations and parameters for pavement structures during construction.

FIGURE 2 Critical stresses and strains in a flexible pavement design (After Powell et al., 1984).

FIGURE 3 Particle size distribution for materials tested in the laboratory. FIGURE 4 Schematic of laboratory test apparatus.

FIGURE 5 Laboratory test mould with portable dynamic plate tester and (appropriate) test positions labeled.

FIGURE 6 Composite stiffness on each compacted layer versus test position for, (a) 'stiff' base condition, (b) 'soft' base condition. FIGURE 7 A summary of laboratory composite stiffness for the sandy gravel on the 'soft' base condition.

FIGURE 8 Water content profiles for the sandy gravel on the soft mould base conditions. 
TABLE 1 Material test data from field trials in the United Kingdom.

\begin{tabular}{|c|c|c|c|c|c|c|}
\hline $\begin{array}{c}\text { Section } \\
\text { No }\end{array}$ & $\begin{array}{c}\text { Material } \\
\text { Description }\end{array}$ & $\begin{array}{l}\text { Layer } \\
\text { Type }\end{array}$ & $\begin{array}{c}\text { Thickness } \\
\text { mm }\end{array}$ & $\begin{array}{c}\text { pdry } \\
\mathbf{M g} / \mathbf{m}^{3}\end{array}$ & $\begin{array}{c}\text { Ecomp } \\
\text { MPa }\end{array}$ & $\begin{array}{c}\text { DCP } \\
\% \text { CBR }\end{array}$ \\
\hline 1.1 & Glacial till & Subgrade & - & - & $16-44^{\$}$ & $3-3.5$ \\
\hline 1.2 & Granodiorite & Sub-base & 280 & 1.99 & $38 * \$$ & 17 \\
\hline 1.3 & & & & 2.06 & $48 * \$$ & 24 \\
\hline 1.4 & & & & 2.09 & $38 * \$$ & 30 \\
\hline 1.5 & & & & $2.08^{£}$ & $128 * \$ \mathfrak{E}$ & $>30^{£}$ \\
\hline 2.1 & $\begin{array}{l}\text { Mercia } \\
\text { Mudstone }\end{array}$ & Subgrade & - & - & $13-19^{\$}$ & $5-6$ \\
\hline 2.2 & Granodiorite & Capping & 450 & $1.60-1.69$ & $32-37^{\$}$ & 11 \\
\hline 2.3 & (40mm down) & & 300 & $1.60-1.69$ & $41-49^{\$}$ & 8 \\
\hline 2.4 & & & 150 & $1.60-1.66$ & $35-44^{\$}$ & 5 \\
\hline 2.5 & Granodiorite & Sub-base & 150 & $1.88-1.97$ & $47-52^{\$}$ & 5 \\
\hline 2.6 & (Type 1) & & 150 & $1.91-1.98$ & $42-46^{\$}$ & 8 \\
\hline 2.7 & & & 150 & $1.90-1.97$ & $30-36^{\$}$ & 7 \\
\hline 3.1 & $\begin{array}{l}\text { Very soft sandy } \\
\text { silty clay }\end{array}$ & Subgrade & - & - & $19^{\$}$ & $2-6$ \\
\hline 3.2 & $\begin{array}{l}\text { Porphyritic } \\
\text { Andesite (6F2) }\end{array}$ & Capping & 450 & $2.05-2.13$ & $43-70^{\$}$ & - \\
\hline 3.3 & $\begin{array}{l}\text { Oolitic Lime- } \\
\text { stone (6F2) }\end{array}$ & Capping & 450 & $1.96-2.04$ & $62-67^{\$}$ & - \\
\hline 3.4 & $\begin{array}{c}\text { Porphyritic } \\
\text { Andesite }(40 \mathrm{~mm} \\
\text { down) }\end{array}$ & Capping & 450 & $1.97-2.10$ & $44-54^{\$}$ & - \\
\hline 4.1 & $\begin{array}{c}\text { Mercia } \\
\text { Mudstone }\end{array}$ & Subgrade & - & - & $37-65^{\$}$ & $15-100$ \\
\hline 4.2 & $\begin{array}{l}\text { Sand, gravel and } \\
\text { limestone }\end{array}$ & Capping & 400 & - & $65-67^{\$}$ & $3-100$ \\
\hline 5.1 & Soft to firm clay & Subgrade & - & - & $12-57^{+}$ & $10-21$ \\
\hline 5.2 & Sandy gravel & Capping & 250 & - & $25-48^{+}$ & $22-52$ \\
\hline 5.3 & (6F2) & & 600 & - & $35-192^{+}$ & $37-105$ \\
\hline 6.1 & Mudstone (6F2) & Capping & $300-600$ & $1.66-2.04$ & $50-120^{+}$ & $9-30$ \\
\hline 7.1 & Crushed & Capping & 395 & $1.68-1.85$ & $151-163^{+}$ & $45-65$ \\
\hline 7.2 & $\begin{array}{l}\text { concrete with } \\
5 \% \text { rubble }(6 \mathrm{~F} 2)\end{array}$ & & 285 & $1.64-1.86$ & $119-209^{+}$ & $17-23$ \\
\hline \multicolumn{3}{|c|}{$\begin{array}{l}\mathrm{DCP}=\text { Dynamic Cone Penetrometer } \\
\text { Ecomp }=\text { Composite stiffness }(\mathrm{MPa})\end{array}$} & \multicolumn{4}{|c|}{$\begin{array}{l}\mathrm{CBR}=\text { California Bearing Ratio }(\% \mathrm{CBR}) \\
\text { pdry }=\text { Dry density }\left(\mathrm{Mg} / \mathrm{m}^{3}\right)\end{array}$} \\
\hline \multicolumn{3}{|c|}{$\begin{array}{l}*=\text { Backcalculated layer stiffness } \\
+=\text { Portable Dynamic Plate Test } \\
£=\text { With artificial subgrade }\end{array}$} & \multicolumn{4}{|c|}{$\begin{array}{l}\$=\text { Falling Weight Deflectom } \\
100 \mathrm{kPa} \text { contact stress applied }\end{array}$} \\
\hline
\end{tabular}


TABLE 2 Material test data assessed in the laboratory mould using the soft base condition.

\begin{tabular}{|c|c|c|c|c|c|c|}
\hline $\begin{array}{c}\text { Material } \\
\text { Description }\end{array}$ & $\begin{array}{c}\text { Thickness } \\
\text { mm }\end{array}$ & $\begin{array}{c}\rho d r y \\
\mathbf{M g} / \mathbf{m}^{3} \\
\end{array}$ & $\begin{array}{c}\text { WC } \\
\% \\
\end{array}$ & $\begin{array}{c}\text { Ecomp } \\
\text { MPa }\end{array}$ & $\begin{array}{c}\text { DCP } \\
\% \text { CBR }\end{array}$ & $\begin{array}{c}\text { Impact H } \\
\text { IV } \\
\end{array}$ \\
\hline $\begin{array}{l}\text { Crushed } \\
\text { Concrete } \\
(6 \mathrm{~F} 2)\end{array}$ & 450 & 1.60 & 8.5 & $36-41(6 \%)$ & $18-23$ & 23 \\
\hline $\begin{array}{l}\text { Mudstone } \\
\text { (6F2) }\end{array}$ & 450 & 2.00 & 8.0 & $36-87(37 \%)$ & $59-63$ & 5 \\
\hline Sandy gravel & 100 & 2.06 & 6.4 & 17-21 (7\%) & - & $6-12$ \\
\hline$(6 \mathrm{~F} 2)$ & 200 & 2.24 & 6.4 & $12-42(14 \%)$ & 23 & $21-31$ \\
\hline & 300 & 2.05 & 6.5 & $45-105(38 \%)$ & 45 & $22-56$ \\
\hline & 400 & 2.21 & 6.5 & $71-145(31 \%)$ & 54 & $20-35$ \\
\hline Granodiorite & 100 & 2.39 & 4.2 & $13-17(11 \%)$ & - & $17-22$ \\
\hline (Type 1) & 200 & 2.44 & 3.9 & $18-28(17 \%)$ & 51 & $38-47$ \\
\hline & 300 & 2.43 & 4.0 & $31-51(18 \%)$ & 97 & $32-42$ \\
\hline & 400 & 2.43 & 4.2 & $18-35(22 \%)$ & 81 & $26-33$ \\
\hline
\end{tabular}

\section{Notes:}

pdry $=$ Dry density $\left(\mathrm{Mg} / \mathrm{m}^{3}\right)$

$\mathrm{WC}=$ Water content

Ecomp $=$ Composite stiffness (Mpa)

$($ value $)=$ Coefficient of Variance $(\%)$

DCP = Dynamic Cone Penetrometer

$\mathrm{CBR}=$ California Bearing Ratio (\% CBR)

Impact $\mathrm{H}=$ Impact hammer $\mathrm{IV}=$ Impact value $\left(\mathrm{x} 10 \mathrm{~g}=\mathrm{ms}^{-2}\right)$ 


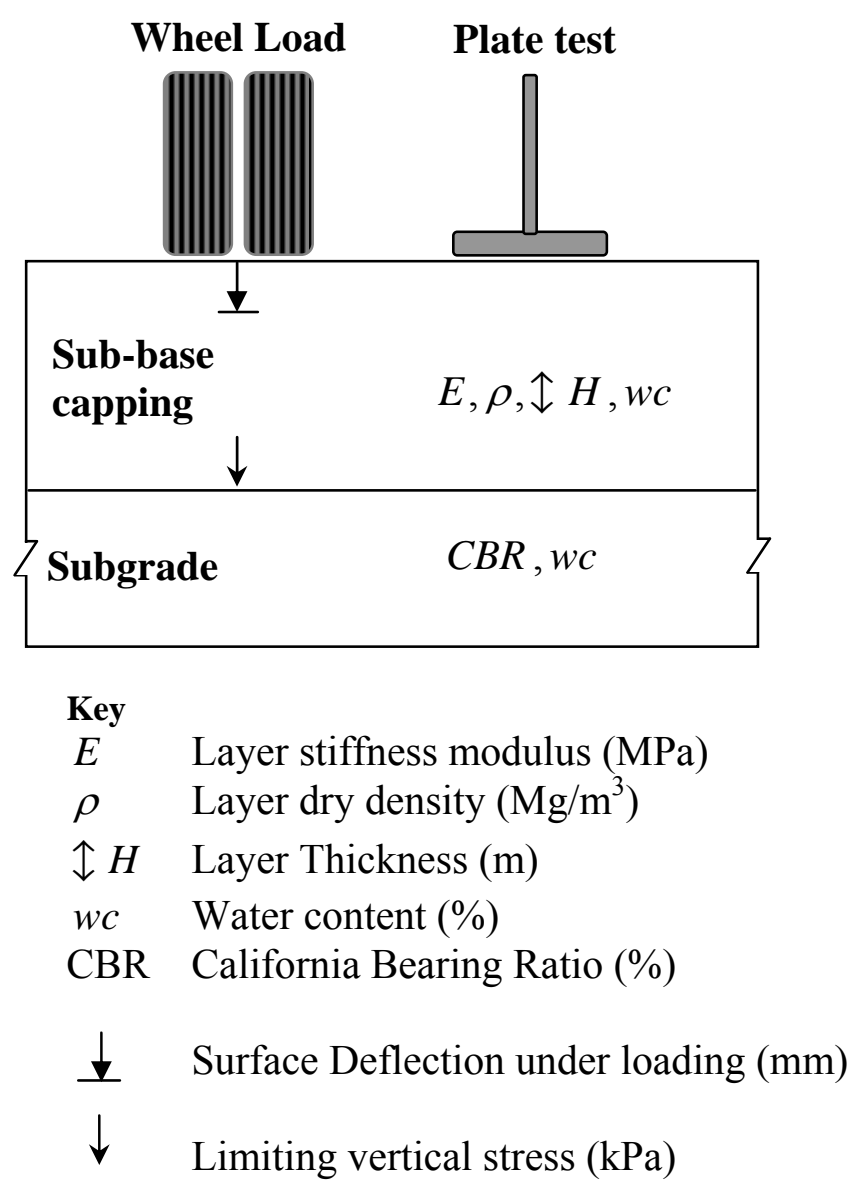

FIGURE 1 Key design considerations and parameters for pavement structures during construction. 


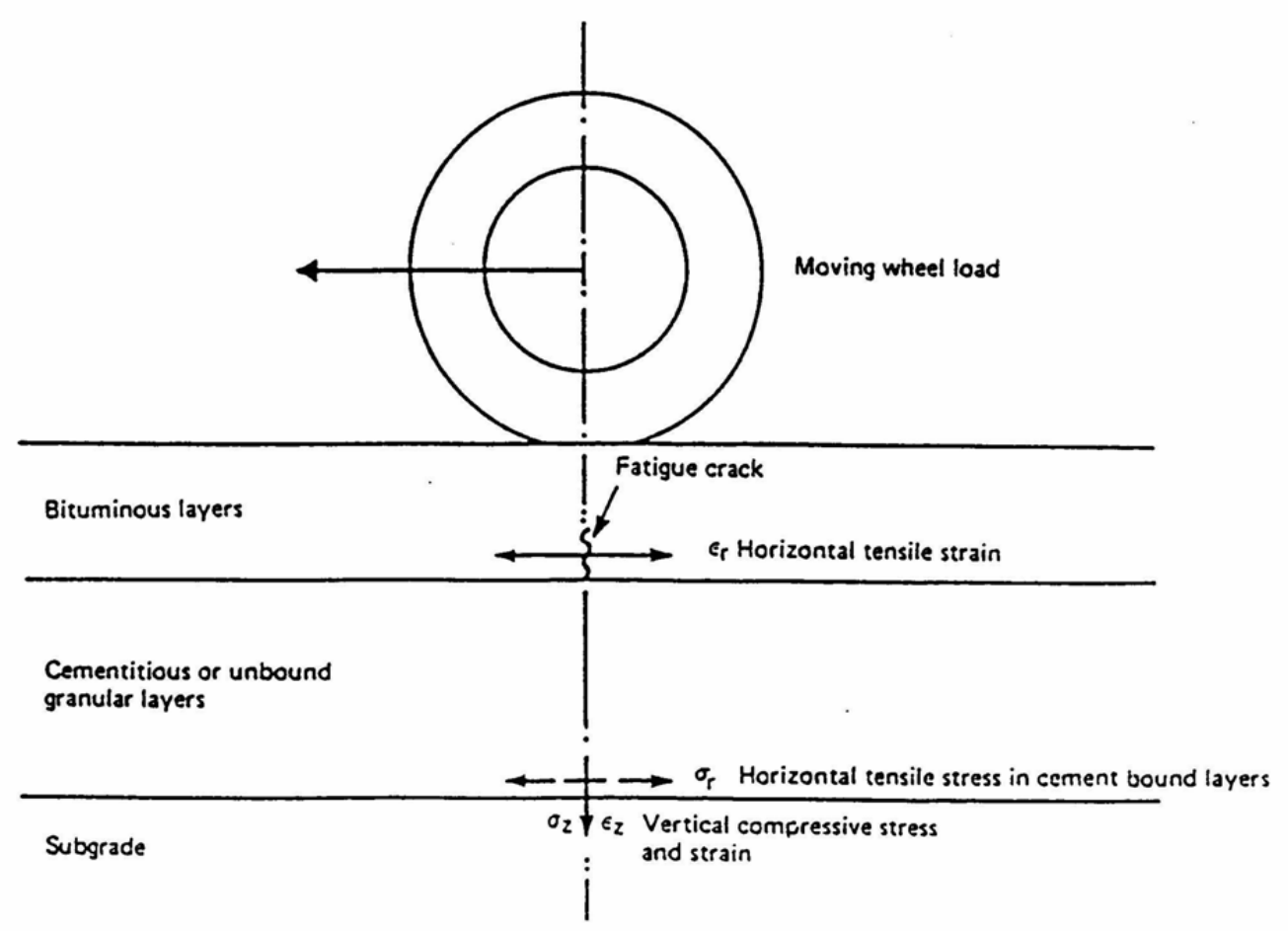

FIGURE 2, Critical stresses and strains in a flexible pavement design (After Powell et al., 1984). 


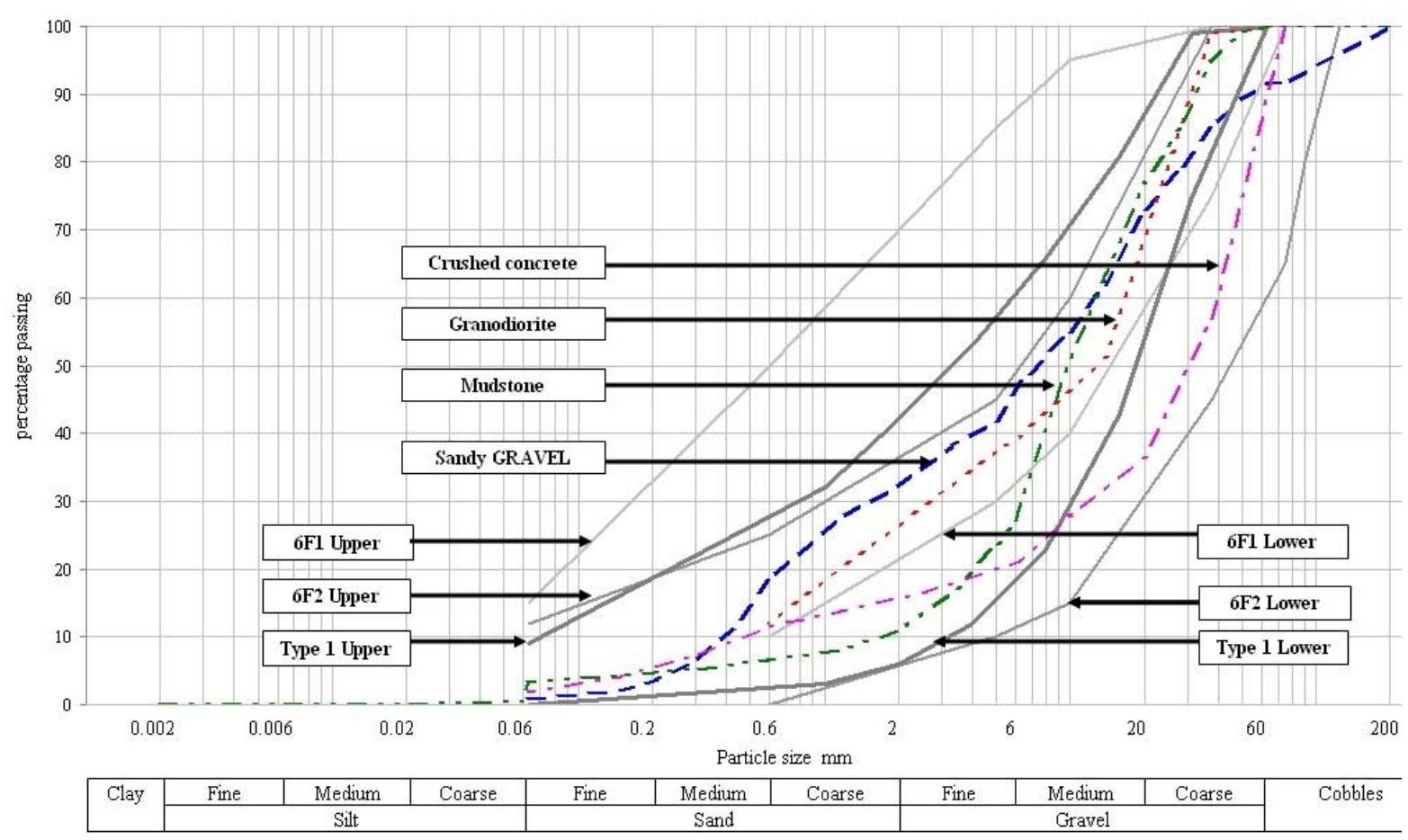

FIGURE 3 Particle size distribution for materials tested in the laboratory. 


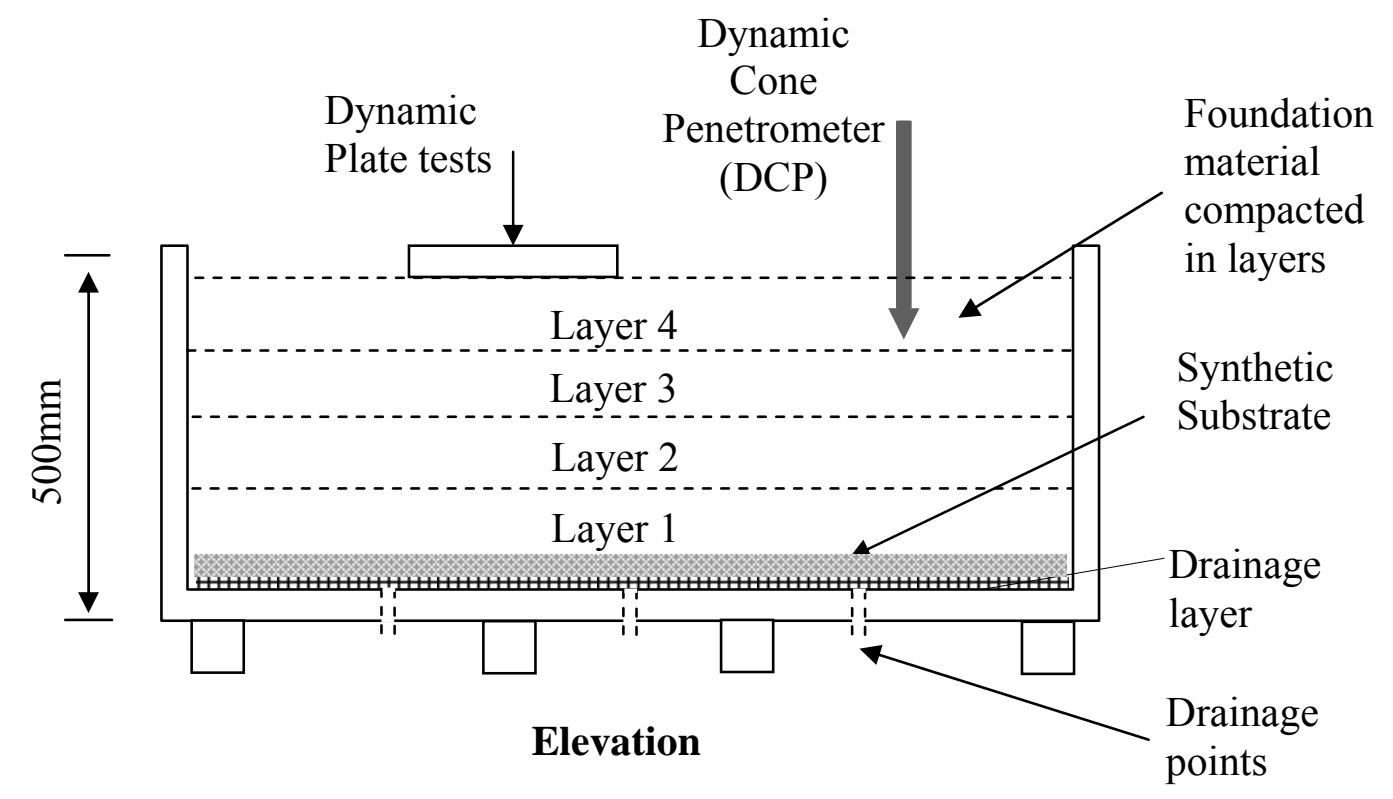

FIGURE 4 Schematic of laboratory test apparatus. 


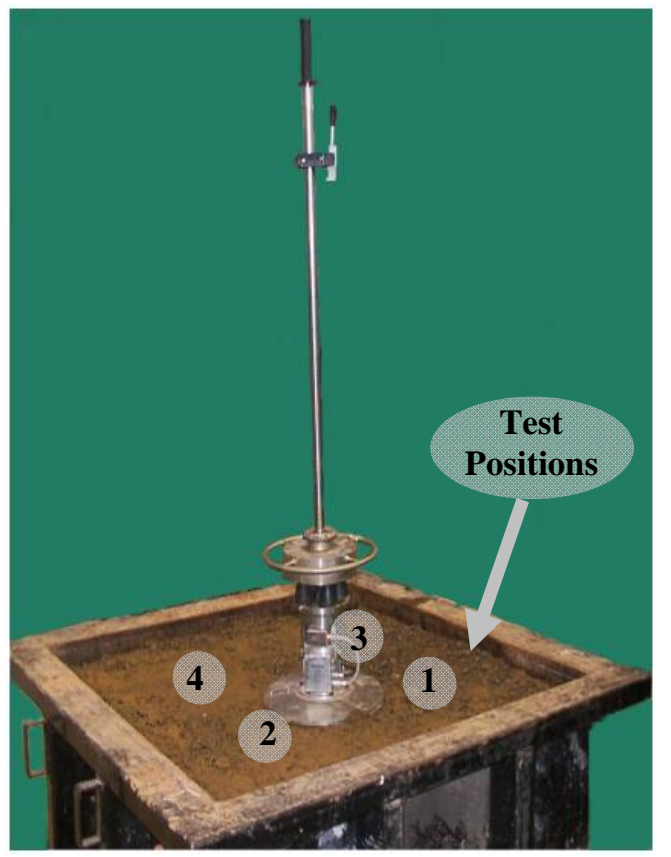

FIGURE 5 Laboratory test mould with portable dynamic plate tester and (appropriate) test positions labeled. 


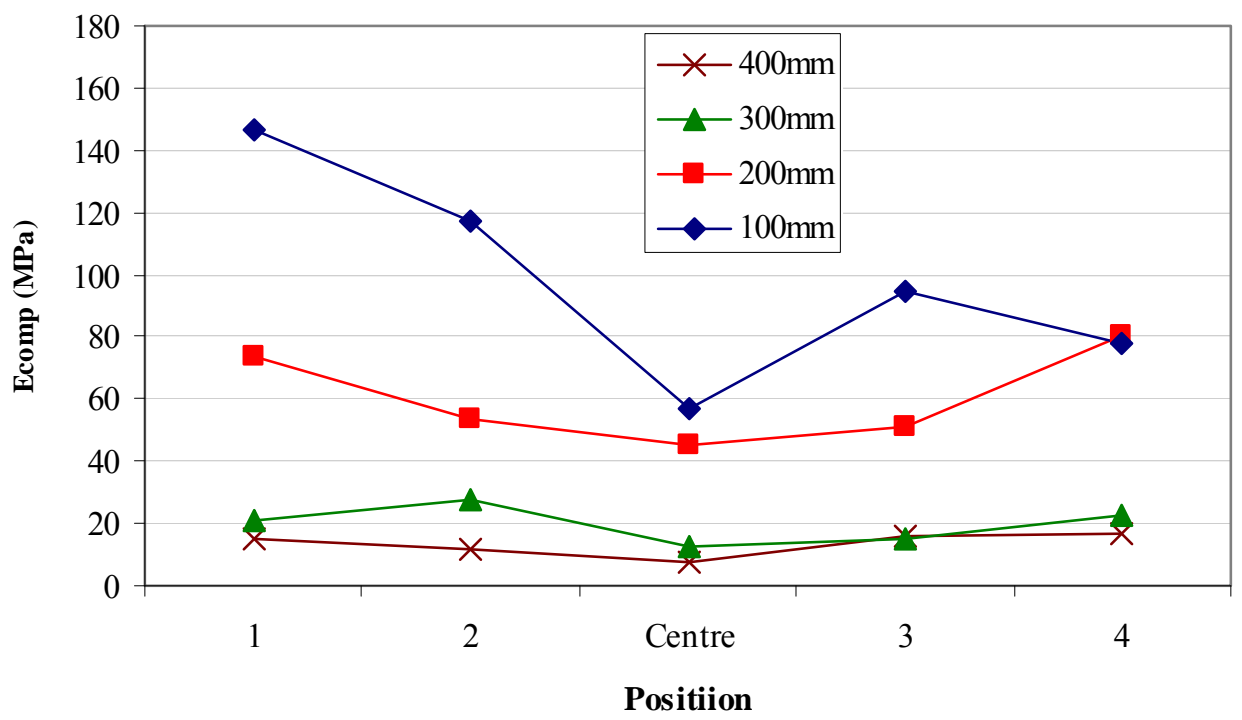

(a)

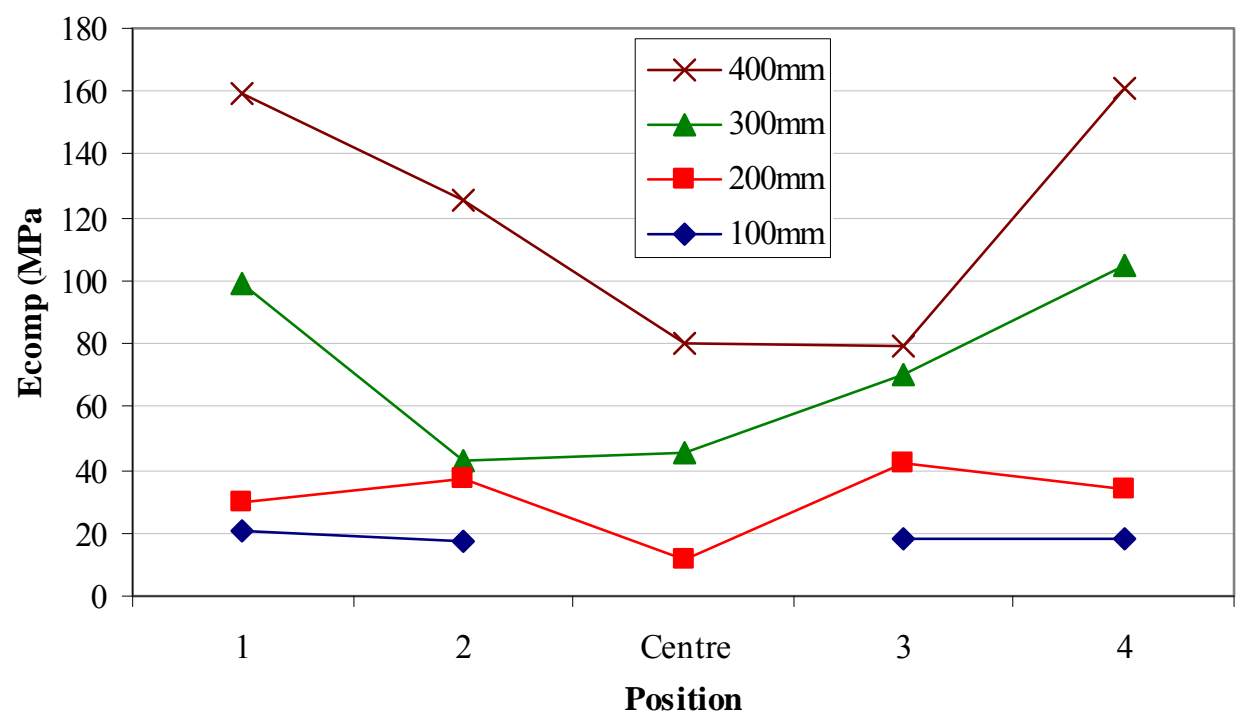

(b)

FIGURE 6 Composite stiffness on each compacted layer versus test position for, (a) 'stiff' base condition, (b) 'soft' base condition. 


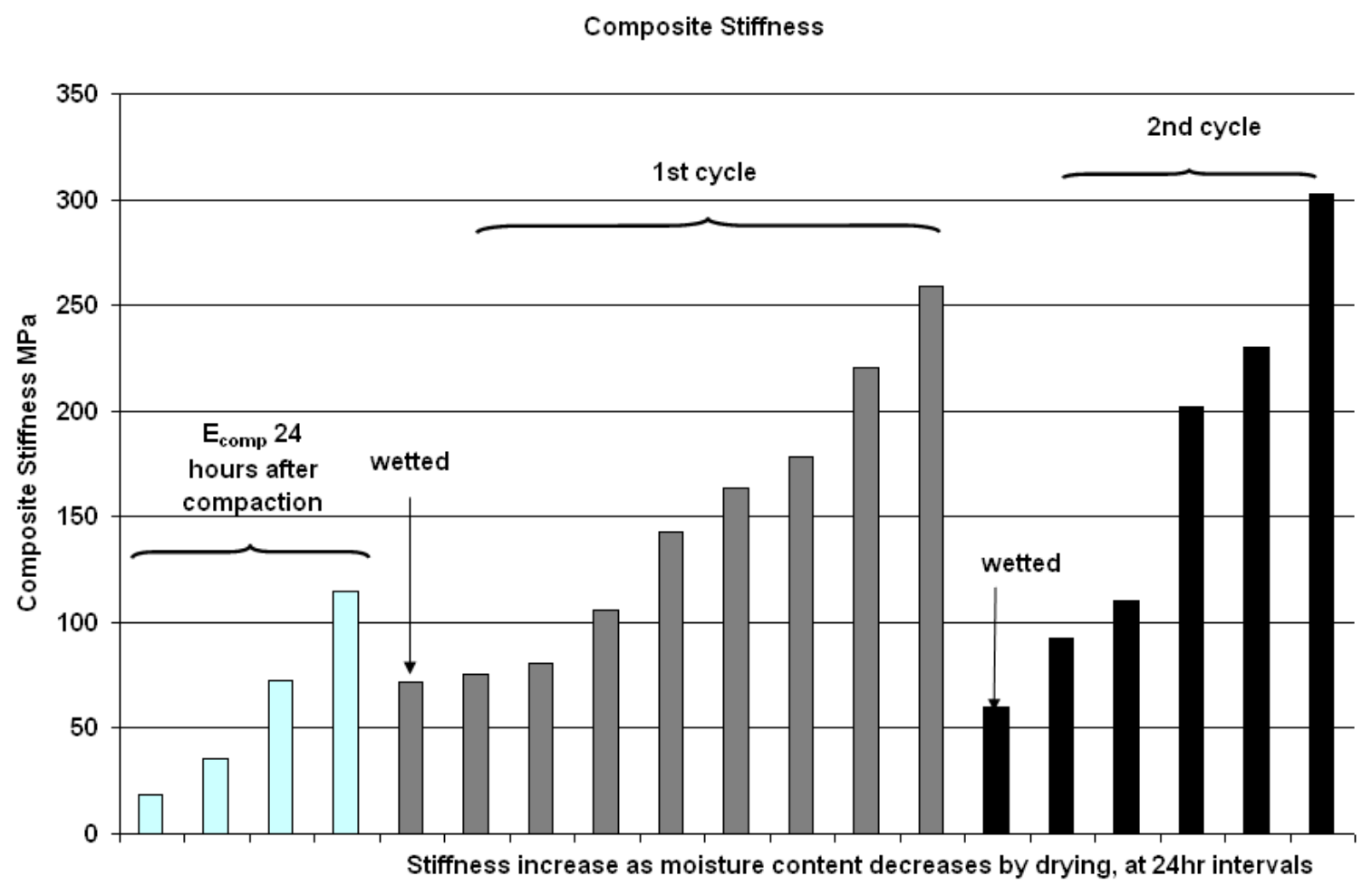

FIGURE 7 A summary of laboratory composite stiffness for the sandy gravel on the 'soft' base condition. 


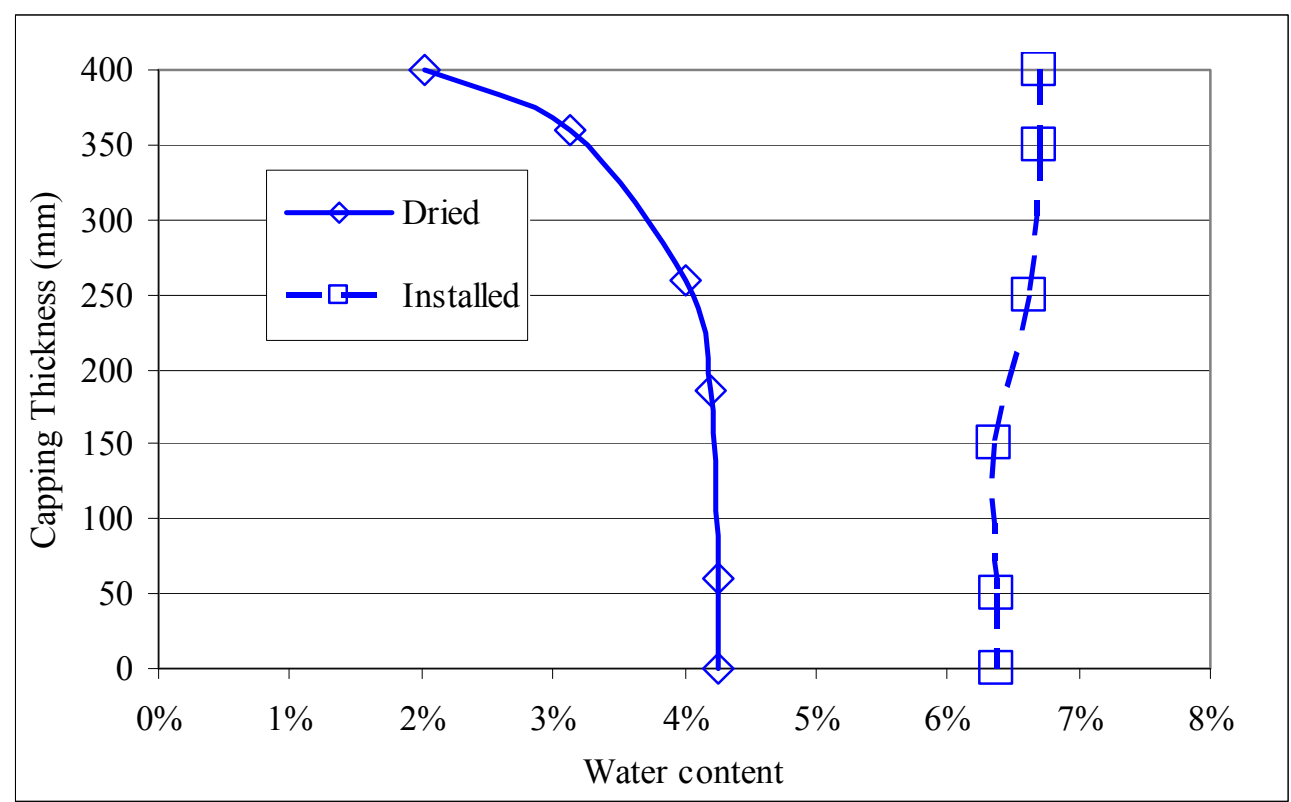

FIGURE 8 Water content profiles for the sandy gravel on the soft mould base condition. 